\title{
EUROCONTROL SLOT ALLOCATION METHODOLOGY AND NEW APPROACH FOR CALCULATED TAKE OFF TIMES (CTOT): ALTERNATIVE CTOT VERSUS CTOT
}

\author{
Ertan ÇINAR ${ }^{1, *}$, Soner DEMIREL ${ }^{1}$ \\ ${ }^{1}$ Department of Air Traffic Control, Faculty of Aeronautics and Astronautics, Anadolu University, Eskişehir, Turkey
}

\begin{abstract}
In ICAO (International Civil Aviation Organisation) Europe Region, the ATFCM (Air Traffic Flow and Capacity Management) is managed by EUROCONTROL (European Organisation for the Safety of Air Navigation) for a long time. Planned ATFCM applications on nowadays and future time periods are not well enough to solve the airport congestion in an effective way. In the present case, main purpose of this study is to give alternative solution suggestions for narrow airport capacity and to ease the parking positions by making new departure time offers to the airline operators. In the scope of this study, to create free parking positions in every hour zone, air traffic flows are arranged from the imaginary airports to the target arrival airport in the MS Office Excel programme. According to the results of the study, to the target airport 10 extra flights per day and 3650 extra flights per year may be arranged. Furthermore, it is considered that only type of aircrafts B737-800 and A320 landed and departed to/from the target airport, 1.327.140 extra passengers may be transported annually, as number of A320 is 4 times more than number of B737-800. The possible advantages and disadvantages of this study are discussed in the result section.
\end{abstract}

Key words: CTOT, ACTOT, Parking Position, ATFCM

\section{INTRODUCTION}

Along with the renovation of transportation technologies, and as a result of the increasing demand for aviation which has a cheaper, safer and more efficient transportation network, existing air traffic is increasing day by day. This situation turns air traffic flow management into a subject to be studied more. The main purpose of air traffic flow management is to provide a more ordered traffic flow in the areas where the capacity is exceeded. Air traffic flow management is not only to manage the traffic; it is also to make the existing limited capacity be optimized.

As a result of the rapidly increasing air traffic, authorities have been trying to search for and develop a solution for the most efficient way to use the existing capacity. According to SAA (State Airports Administration) annual flight traffic data, the number [1] of air traffic for the last 9 years is shown in Table 1. For the flight traffic data, month of January was chosen in every year as reachable data for all year 2007-2015 and it was considered that traffic rise of winter season can give some clues about the summer season for Turkey. 
Table 1. Flight traffic data belonging to years 2007-2015

\begin{tabular}{|c|c|c|c|c|c|c|c|c|c|}
\hline & \multicolumn{7}{|c|}{ JANUARY } \\
\hline YEARS & 2007 & 2008 & 2009 & 2010 & 2011 & 2012 & 2013 & 2014 & 2015 \\
\hline $\begin{array}{c}\text { SAA } \\
\text { Total }\end{array}$ & 39.577 & 41.271 & 42.076 & 48.929 & 54.273 & 57.719 & 65.417 & 73.090 & 76.492 \\
\hline $\begin{array}{c}\text { Percentage } \\
\text { Increase }\end{array}$ & ---- & $\mathbf{4 , 2 8 \%}$ & $\mathbf{1 , 9 5 \%}$ & $\mathbf{1 6 , 2 9 \%}$ & $\mathbf{1 0 , 9 2 \%}$ & $\mathbf{6 , 3 5 \%}$ & $\mathbf{1 3 , 3 4 \%}$ & $\mathbf{1 1 , 7 3 \%}$ & $\mathbf{4 , 6 5 \%}$ \\
\hline $\begin{array}{c}\text { Turkey } \\
\text { General }\end{array}$ & 42.422 & 44.918 & 45.935 & 55.844 & 63.473 & 66.297 & 75.163 & 87.649 & 92.226 \\
\hline $\begin{array}{c}\text { Percentage } \\
\text { Increase }\end{array}$ & ---- & $\mathbf{5 , 8 8 \%}$ & $\mathbf{2 , 2 6 \%}$ & $\mathbf{2 1 , 5 7 \%}$ & $\mathbf{1 3 , 6 6 \%}$ & $\mathbf{4 , 4 5 \%}$ & $\mathbf{1 3 , 3 7 \%}$ & $\mathbf{1 6 , 6 1 \%}$ & $\mathbf{5 , 2 2 \%}$ \\
\hline
\end{tabular}

It is possible to say in the light of this data that air traffic flow for January for 9 years has increased each year. For instance, in 2007, traffic 42,422 and in 2008 traffic 44.918 . So, it increased as 5,88\% during 1 year (2007-2008). This also demonstrates that the demand and capacity experienced in the previous year has not been the limit yet. However, there will be an end for this increase and the system will stop.

According to air traffic capacity predictions in the article called "Task 4: European Air Traffic in 2035" of an edition named "Challenges of Growth 2013", 1.9 millions of flight will not have a parking position in airports in 2035 and the flights will not be performed. 1.9 millions of flight means the $12 \%$ of the whole demand [2]. The analysis on necessary sources and capacity for today's air traffic demand and air traffic management offers an insight that most of the future plans will be interrupted under these circumstances. It is approved under these circumstances that it is necessary to employ airports and air spaces with limited capacity in the most effective and efficient way.

The subject of employing airport capacities in a more efficient way which is the focal point of our study is tried to be performed through slot allocations today. Slot practices in Europe are applied to all flights that take off from ATFCM airspace, are the subjects of ATFCM slot allocations or to all flights which take off from a neighbouring airspace and land on ATFCM airspace [3]. Within this context, ATFCM is a service, which improves ATFM (Air Traffic Flow Management), to increase the quality and performance of the given service by using existing sources and solutions in an efficient way in order to create a demand and capacity balance [3].

ATFCM is applied at 4 stages in ECAC (European Civil Aviation Conference) zone. These stages are mentioned below respectively;

i. Strategy flow management: It starts 7 days or more before the operation. Researching, Planning and Coordination studies are carried out in this process. The output of this stage is NOP (Network Operation Plan). Demand/Capacity imbalances are researched. When such a condition was detected NM (Network Management) becomes responsible from it and strategic ATFCM performs the planning.

ii. Pre-tactical flow management: This stage starts 6 days before the operation. Planning and coordination are carried out in this process. The output of this stage is ADP (ATFCM Daily Plan). These plans are published by ATFCM Notification Message or NOP portal.

iii. Tactical flow management: This stage starts on the day of the operation. Situations affecting ADP and which are needed to be regulated are handled real-timely. The situations may be due to staff, weather conditions etc. original plan can be modified both for nettlesome situations and for opportunities to be turned into advantages. 
iv. Post-operation analysis: At this stage, evaluation, which is performed after operation is completed, is done in order to obtain a feedback. Feedback should be also obtained from companies. At this stage, expected results about ground delay and re-routing are compared to real outputs.

Applied slot is quite important for the efficient and effective use of existing capacity. It also has the qualification of a solution for congestions in airports [3]. Slot is the process of allocating specific time for flights to take off and land on. [4].

Slot allocation system today has a semi flexible usage. After the slots are determined, all the lines are drawn and planning is completed. However, slots limit the companies in a way. Flow management which is very efficient for capacity and congestion at the airport can not provide a special flexibility for all the users. In this sense, this study is both going to provide slots, which are allocated due to capacity and substructure shortages, to attain their purposes, and it is also going to provide companies to use these airports in a more efficient way in existing capacity constraints and bring flexibility. In this way, both capacity constraints are followed and a more dynamic and flexible structure is provided for slot allocation process. Suggested method in this study is going to provide slot allocation processes the ability to be utilized by air traffic controllers, airport managers, airline companies and passengers in a wider and mutual way.

\section{PREVIOUS STUDY SAMPLES}

This study gives to the more basic and essential approach to the system and method of the system to solve the airport congestion. It is not only focused on delays and airport congestion but also, subjected as ease of parking positions and creating free parking positions in order to make the system more flexible while solving the congestion in the airport by changing slot allocation methodology to the new one.

Previous studies were searched. As a result of these researches various articles and researches were found. Studies which were chosen from these searches and most related ones are mentioned under this subtitle.

A study carried out by Abeyratne in 2000 mentions especially about how the management of empty slots, which are in the airports, where congestion is experienced, turns into a challenging factor. This is a situation which affects the capacity of the airports. Airport management performed by the method of slot allocation is an important subject to be thought about [4].

In a study carried out by Barbot in 2004, it is known that air transportation competition principles encounter a lot of obstacles. Lack of mobilization of airport slot is one of these obstacles. European Commission prepares a regulation to use the capacity in an efficient way. Possible outputs of such a plan were analysed in the study. A model that apprehends the main frame of airport market situation before and after the slot reallocation process was used. Repetition of grandfather rule shows that the companies which use the slots $80 \%$ more efficient in a period, have the right to reuse the same slots in the following period. It is stated in the study that the distribution of slots between companies is a complicated process, and the reason of the difficulties in practice is that the slots are significant when they are paired as take off - landing, landing - take off [5].

According to another study carried out by Madas and Zografos, the general usage purpose of slot allocation is to manage ground delay and capacity lowness. This article aims to create various strategies by using previous studies. The management of the demand for the need of operation has a great importance for the future. As it is stated in the study, there is a low relationship between economical costs of the airport fees and the use of the facilities at airport. However, this situation is generally proportional in term of the cost of substructure use and MTOW (max. take-off weight) [6]. 
In a study carried out by Forsyth, it is stated that the demand for the airport substructure is changing and increasing day by day. Demand increase for the limited capacity allocation creates some problems. How slot system is facing with the situation is analysed. These problems expressed as short term problems are demand improvement and airport capacity allocation. At this stage, there are two significant subjects in capacity allocation;

i. Slot systems in the busiest airports except U.S. and

ii. Fee structure of airports.

As a part of a significant congestion, there are a lot of benefits of slot system. Slot system keeps the demands in the capacity for a reasonable fee. Not being allocated in an efficient way of slots is the disadvantage of the slot system [7].

Roosens focuses on the short term operational techniques about the use of capacity in an ideal way in his study. Solutions about the improvement of the airport capacity have been discussed by economists. Main agenda topic of this discussion is the congestion based costs and main pricing for airport slot allocation solutions [8].

In a study carried out in 2009, the topic is the researches about CDM (Collaborative Decision Making) which was first applied in Munich airport and which was later applied in 42 more airports. Airport CDM project is about the turnaround procedures of the aircrafts. One of the results obtained after CDM is TTOF (Target Take-off Time) which develops ground planning and helps area planning [9].

This article aims to present a study that helps the solution of a problem of creating a contingency plan for the management of air traffic flow and capacity. In the article, it is stated that ATFCM manages approximately 30.000 flights in 1500 aerodromes in total on an ordinary day. Hourly take off slot numbers for airports in general sense are described in the study [10].

In the study carried out by Schaefer and Tene, planned and realized turnaround times are analysed by examining the quality performance data of the companies. 40 minutes of turnaround time is performed for the large part of flights [11].

In a thesis study for Stockholm TMA capacity analysis by Rydin how landing proportions affect arrival output is analysed. One of the highlighted results is that it is possible that there will be maximum 42 landing traffic in a suitable runway configuration due to the density and complexity of existing traffic [12].

\section{PRACTICE AND ACCEPTANCE}

This study is important in the narrow airports for giving flexibility to the system which is getting to congestion in airports step by step. Ease of the airport may be provided by creating more flexible departure times in the system. Also, this method may be useable for the extraordinary situations to be quicker than the expected emergency situations, as volcanic eruption, weather change etc.

In this study, virtual airports (A, B, C, D, E, F, G, H, I, J, K, L and X) and the flights between these airports are diagrammatized. 


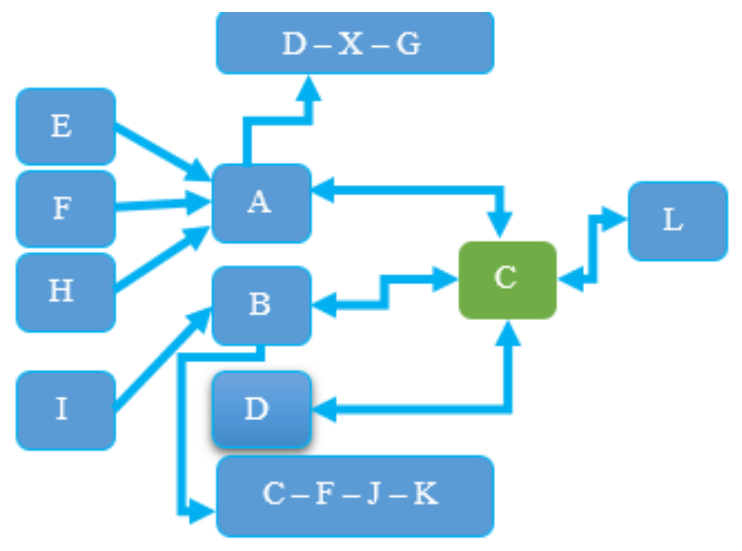

Figure 1. Flight traffic between airports

One way arrows indicate that the traffic has one sided flow and two way arrows indicate that the traffic has two sided flow.

General acceptance about our practice is like the below;

$>$ Take off airports: A, B, D, E, F, H, I and L,

$>$ Target arrival airport: $\mathrm{C}$,

$>$ Parking positions at target arrival airport: G1, G2, G3, G4, G5,

$>$ Flight time: $\mathrm{A} \rightarrow \mathrm{C}$ ( 2 hours), $\mathrm{B} \rightarrow \mathrm{C}$ (1 hours), $\mathrm{D} \rightarrow \mathrm{C}$ ( 3 hours) and $\mathrm{L} \rightarrow \mathrm{C}$ ( 2 hours). By taking into the performed flight operations, flight time is determined,

$>$ Take off and landing time and airport working hours are determined by us as per the scenario,

$>$ Turnaround time: Turnaround time, which is determined as 30 minutes in a research, and which is determined as 40 minutes for $\mathrm{C}$ airport, is performed in 42 minutes. We determined this time as 40 minutes by taking the type and category of the aircraft and traffic density into account [11],

$>$ Flight take off and landing intervals: Take off and landing intervals per unit hour and airport capacity situations are determined by being accepted on a common denominator. 5 aircrafts, which are in the same time zone and successive of each other, perform take off and landing with 2 minutes separation between two aircrafts in common. According to the DOC4444 separation of medium before heavy aircraft is 2 minutes so, in the study 2 minutes is determined for common denominator [13].

> Parking position allocations are performed by checking EOBT of the landing aircraft and allocating equally with related time zone or by comparing the following aircraft's landing time. For instance, if the estimated landing time for F1 is 10:00 and if the EOBT time of the aircraft parked at G1 position is 09:55, G1 position is allocated for F1 aircraft. If the landing time is later it creates a capacity excess and parking position is not allocated,

$>$ It is accepted that the flights perform their landings at airports without having any emergencies or strike, technical problems, meteorological events and in comply with CTOT and flight duration,

$>$ It is assumed that these flights, which are chosen among all the flights, confirm ACTOT (Alternative Calculated Take-off Time) proposal,

Figure 1 shows the flow of the scenario. According to this figure, there are indirect departure airports as E, F, H, I and direct departure airports which are connected to the target airport directly as A, D, B and L. Direct departure airports also are arrival airports which the flights came from target airport to these airports. There is a target airport which is airport $\mathrm{C}$ and some arrival airports as $\mathrm{C}, \mathrm{D}, \mathrm{F}, \mathrm{G}, \mathrm{J}, \mathrm{K}$ and $\mathrm{X}$ 
which take the flights from direct departure airports. It is noticed that $\mathrm{C}$ airport is the target airport and two-way arrows represents two way of transportation among the airports, except one way arrows.

All the data related to scenario is formed using Microsoft Excel 2013 and necessary calculations are performed with the same program. According to take of time determined at calculations it is assigned that $\mathrm{EOBT}=\mathrm{CTOT}-10$ (minutes).

Convenience of parking positions is checked by a formula created on Microsoft Excel 2013.

\subsection{Practice Scenario}

The practice is started at 11:30 am. This time is determined by the time zones at $\mathrm{C}$ (arrival airport).

It is assumed in the practice that first 5 flights taking off from $\mathrm{A}$ airport with a separation of 2 minutes and fly to $\mathrm{C}$ airport. In the next time zone, it is assumed that 5 aircrafts taking off from $\mathrm{B}$ and fly to $\mathrm{C}$ airport. In the following time zone, it is assumed that 5 aircrafts take off $\mathrm{L}$ airport and fly to $\mathrm{C}$ airport. Then in the next two time zones, 10 aircrafts from $\mathrm{D}$ airport take off fly to $\mathrm{C}$ airport. Take off diagram is shown in Figure 2.

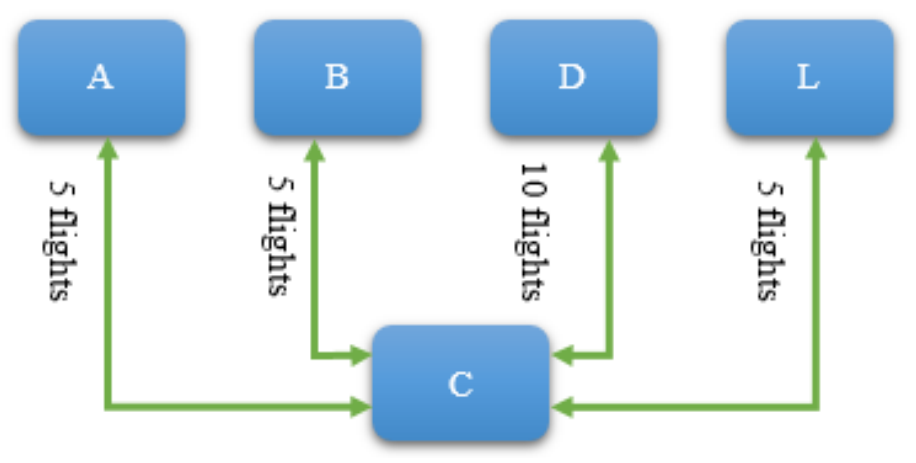

Figure 2. Take off diagram

By assigning ACTOT for the first flights of the flight sets from four airports (A, B, D and L), an empty parking position in $\mathrm{C}$ airport is tried to be created in present situation. In this way, it is checked if it is possible to allocate another flight between the flight with ACTOT and other 4 flights.

This scenario continues from 11:30 am to $4: 48 \mathrm{pm}$ (the time when the last landing aircraft at $\mathrm{C}$ airport takes off from the airport). 5 flights in total are assigned with ACTOT and take off and there is a 125 minutes of expansion at $\mathrm{C}$ airport in total. By using 12 minutes of this 125 minute expansion, 2 extra flights are added for each flight set.

These extra flights are planned to land 2 minutes later than the previous flight and in this sense they are suitable for general time and separation rules of the scenario. 10 aircrafts are planned as extra, 2 aircrafts for each of the time zone in a day, without affecting the existing traffic and also without changing the number of parking position in present situation. It is formed by bringing CTOTs of aircrafts 25 minutes forward than their normal flight plans and then offered.

\section{PRACTICE RESULTS - ADVANTAGES and DISADVANTAGES of ACTOT}

While the number of traffic is 25 according to the grounded flight plan and CTOTs in the study, when new ACTOT is allocated to just 5 flights, this number increases 35 with +10 . Obtained daily and annual traffic increase is given in Table 2. 
Table 2. The number of daily and annual flights and predicted number of flight increase

\begin{tabular}{|c|c|c|c|}
\hline & CTOT & ACTOT & Extra Flight \\
\hline Daily & 25 & 35 & +10 \\
\hline Anпиal & 9.125 & 12.775 & +3.650 \\
\hline
\end{tabular}

By assuming that all existing flights are flown by B737-800 (Boeing) and A320 (Airbus), the number of passengers increase as it is shown in Table 3. Maximum passenger transport capacity of a type of aircraft B737-800 is 189 [14]. This number is 180 for an A320 [15]. In this calculation, it was considered that number of $\mathrm{A} 320$ is more than number of B737-800 in 4 times.

Table 3. Statistics of the number of passengers and the increase in the number of passengers

\begin{tabular}{|l|c|c|c|c|}
\hline Annual & B737-800 & A320 & $\begin{array}{c}\text { Total number of } \\
\text { passengers }\end{array}$ & $\begin{array}{c}\text { The number of extra } \\
\text { passengers }\end{array}$ \\
\hline Round-trip (CTOT) & 689.850 & 2.628 .000 & 3.317 .850 & \multirow{2}{*}{$+1.327 .140$} \\
\cline { 1 - 3 } Round-trip (ACTOT) & 965.790 & 3.679 .200 & 4.644 .990 & \\
\hline
\end{tabular}

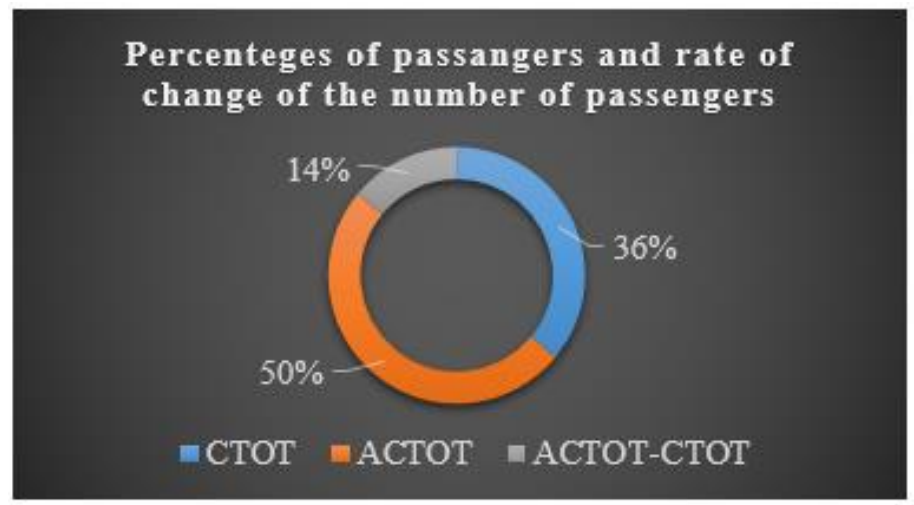

Figure 3. Percentage of the number of passengers and percentage increase performed by ACTOT practice

While creating ACTOTs, the main purpose is to increase existing capacity without changing the possibilities. In accordance with this purpose, introduction of ACTOT which is a new concept and its advantages and disadvantages are

\section{Advantages;}

- ACTOT provides flexibility to pre-planned flights and slots.

- It leads steps which increase the existing capacity of landing fields.

- By allocating dynamic ACTOTs towards daily emerging situations, which can not be predicted, the incident can be performed earlier without being affected by extreme situations.

- When take off flights accept ACTOT; slots, which become vacant in this aerodrome, will be filled via new flight plans. To create such vacant slots especially in bigger aerodromes may provide extra flight plans or moves that save the day. 
- It will be possible to add additional trips to influential take off airports for different companies or companies that accept ACTOTs as chain reaction.

- There will be a massive increase in the capacity of passenger transport. It will ease the calculation of passenger capacity for future periods as the year 2035.

- It will increase the landing airport capacity. It will have a great importance in terms of charge policy of new flight plans.

- In case of applying on popular airports, aerodrome capacity, passenger capacity, company profitability and charging profitability will increase.

\section{Disadvantages;}

- If flights which are offered with ACTOTs are not accepted by related companies, not all of the expected extra flights can be performed.

- Passengers will be asked to be ready 1 hour 45 minutes before domestic flights and 2 hours before foreign flights at the gates where their flights with new ACTOTs will take off.

- Since performing flights with ACTOTs is completely an offer- acceptance process, both CTOT and ACTOT have to be announced.

- ACTOT may be more preferable option if companies which do not accept ACTOT are given discount on charging without exceeding costs.

- In order to trial of this method, it was accepted that all flights had on-time operation. But, when it was move it to the real operational environment, it may not be as good as trial version. However, this study is basic and essential for the calculation and not so far from the real operation in most of way. It can be harmonized with operational environment and may be compared with trial version of it.

It is clear that this method is initial period of development. This trial version of this method shows that it may be realised in the real environment to ease of parking positions on narrow airports and giving flexibility to the slot system.

\section{REFERENCES}

[1] SAA website, Retrieved from http://www.dhmi.gov.tr/istatistik.aspx.

[2] Eurocontrol. Challenges of Growth 2013, Task 4: European Air Traffic in 2035. Eurocontrol 2013

[3] Eurocontrol. ATFCM User Manual - Network Operations. 20th ed. Eurocontrol, 2015.

[4] Abeyratne RIR. Management of airport congestion through slot allocation. Journal of Air Transport Management 2000; 6: $29-41$.

[5] Barbot C. Economic effects of re-allocating airports slots: a vertical differentiation approach. Journal of Air Transport Management 2004; 10: 333 - 343.

[6] Madas MA, Zografos KG. Airport slot allocation: from instruments to strategies. Journal of Air Transport Management 2006; 12: 53 - 62.

[7] Forsyth P. The impacts of emerging aviation trends on airport infrastructure. Journal of Air Transport Management 2007; 13: $45-52$.

[8] Roosens P. Congestion and air transport: a challenging phenomenon. European Journal of Transport and Infrastructure Research 2008; 8: 137 - 146. 
Çınar and Demirel / Anadolu Univ. J. of Sci. and Technology A-Appl. Sci. and Eng. 18 (1) - 2017

[9] Modrego EG, Iagaru MG, Dalichampt M, Lane R. Airport cdm network impact assesment. In: Eighth USA/Europe Air Traffic Management Research and Development Seminar; 29 June - 2 July 2009; Napa, California USA. ATM 2009.

[10] Blomdahl KS, Flener P, Pearson J. Contingency plans for air traffic flow and capacity management. In: 9th Innovative Research Workshop \& Exhibition; 7-9 December 2010; EUROCONTROL Experimental Centre in Brétigny-sur-Orge, France. Brétigny-sur-Orge, France: SESAR WPE. pp. 119126.

[11] Schaefer L, Tene N. Aircraft turnaround times for air traffic simulation analyses. In: Transport Research Board 2003 Annual Meeting 2003.

[12] Rydin A. Stockholm TMA capacity - a study of the landing rate and its effects on arrival outcome. MSc, Linköping University, Norrköping, Sweden, 2014.

[13] International Civil Aviation Organisation. Doc 4444 Procedures for Air Navigation Services - Air Traffic Management 15th ed. ICAO, 2007.

[14] Boeing website, Retrieved from http://www.boeing.com/commercial/737ng.

[15] Airbus website, Retrieved from http://www.airbus.com/aircraftfamilies. 